Atıf için / For Citation: D. D. İzci, M. Yılmaz, "HD 199719'un çizgi ortay analizi", Süleyman Demirel Üniversitesi Fen Edebiyat Fakültesi Fen Dergisi, 15(1), 90-99, 2020.

\title{
HD 199719’un Çizgi Ortay Analizi
}

\author{
Didem Dilan İZCI ${ }^{* 1}$, Mesut YILMAZ ${ }^{2}$ \\ ${ }^{1}$ Ankara Üniversitesi, Fen Bilimleri Enstitüsü, Astronomi ve Uzay Bilimleri Bölümü, 06100, Ankara, \\ Türkiye \\ ${ }^{2}$ Ankara Üniversitesi, Fen Fakültesi, Astronomi ve Uzay Bilimleri Bölümü, 06100, Ankara, Türkiye \\ *yazışllan yazar e-posta: ddizci@ankara.edu.tr
}

(Alınış / Received: 17.01.2020, Kabul / Accepted: 06.04.2020, Yayımlanma / Published: 31.05.2020)

Özet: Bu çalışmada, TÜBİTAK Ulusal Gözlemevinde (TUG) devam etmekte olan ötegezegen araştırmasının bir parçası olarak HD 199719'un tayfsal çizgi ortaylarının (bisektör) değişimleri incelendi. Gözlemsel tayflara bir şablon tayf ile çapraz korelasyon fonksiyonları (CCF) uygulanarak, ortalama çizgi profilleri elde edildi. Bu profillerden çizgi ortayları belirlendi. $\mathrm{Bu}$ çizgi ortaylarını nicel olarak tanımlamak için çizgi ortay ölçütleri kullanıldı. Bu ölçütler ile çizgi profillerindeki hız alanları hesaplandı ve dikine hız ölçümleri arasındaki ilişki araştırıldı. Yıldızın doğası kaynaklı (bulgurlanma (granülasyon), zonklama (pulsasyon), manyetik etkinlik kaynaklı yüzey lekeleri ve manyetik çevrim gibi) etkileri araştırmak için çizgi ortayların yanı sıra, $H \alpha$ ve $H \beta$ çizgilerinin eşdeğer genişlik ölçümleri de yapıldı. Yıldızın çizgi ortay hız ile dikine hız değerleri arasında bir korelasyon olmadığı görüldü. Çizgi ortay hız ölçümleri (BIS ve BVC) için yapılan dönem analizlerinde 4.88 ve 10.36 günlük dönemleri işaret eden pikler elde edildi. Ho'nın eşdeğer genişlik ölçümleri için uzun dönemli bir değişim olabileceği görülse de, benzer bir değişim H $\beta$ 'nın eşdeğer genişlik ölçümlerinde elde edilmedi.

Anahtar kelimeler: Yıldızlar, Dev yıldızlar, Ötegezegenler, Çizgi ortayı, Dikine hız, Çapraz korelasyon fonksiyonu

\section{Bisector Analysis of HD 199719}

Abstract: In this study, an analysis of spectral line bisector variations for HD 199719 which was examined as a part of the exoplanet studies that carried on the TÜBİTAK National Observatory (TUG). Cross-correlation functions (CCF) were implemented to the observed spectra using some template spectra to determine mean line profile. Line bisectors were derived from mean line profiles. In order to quantify asymmetries on the line profiles, some bisectors criteria were used. The velocity spans were calculated in the profiles with these criteria and correlation between the star's radial velocity measurements were investigated. In addition, equivalent width measurements of the $\mathrm{H} \alpha$ and $\mathrm{H} \beta$ were performed to check other variability due to nature of star (granulation, pulsation, magnetic cycle and stellar spots due to activity). No correlation has been found between the radial velocity and line bisectors measurements. Period analysis for bisectors (BIS and BVC) show that significant periodicity appearing around 4.88 and 10.36 days. Although there was a long-term variation for the equivalent width measurements of $\mathrm{H} \alpha$, a similar change was not obtained for equivalent width measurements of $\mathrm{H} \beta$.

Key words: Stars, Giant stars, Exoplanet, Bisector, Radial velocity, Cross-correlation function 


\section{Giriș}

Günümüzde ötegezegen keşifleri için birçok yöntem kullanılmaktadır. Bunlardan en yaygın kullanılanlardan birisi de dikine hız $(\mathrm{DH})$ yöntemidir. $\mathrm{Bu}$ yöntem temelde yıldızların tayf çizgilerinde ki göreli Doppler kaymalarının ölçümüne dayanmaktadır. Bir yıldız etrafında gezegen(ler)in varlığı söz konusu ise bu gezegen(ler) kütle çekim etkisi sebebiyle yıldızda oldukça küçük bir Doppler kaymasına sebep olacaktır. Bu kaymanın mertebesi ise birkaç $\mathrm{msn}^{-1}$ civarındadır. Ancak yıldızların tayflarında bu mertebelerde Doppler kaymalarına sebep olan tek etki bu değildir. Bunların yanında yıldız zonklaması (pulsasyonu), bulgurlanma (granülasyon), manyetik çevrim ve yüzey lekeleri gibi başka etkenler de mevcuttur. Örneğin, sakin bir manyetik aktiviteye sahip bir yıldızda tipik dikine hız değişim mertebesi $0.5 \mathrm{~ms}^{-1}$ civarındayken, aktif bir yıldız için ise bu değer birkaç $\mathrm{msn}^{-1}$ den birkaç yüz $\mathrm{ms}^{-1}$ mertebelerine kadar değişebilmektedir [1,2]. Zonklama yapan bir yıldız için ise bu değişimler yıldız türüne ve evrimsel aşamaya bağlı olarak birkaç $\mathrm{ms}^{-1}$ ile $400 \mathrm{msn}^{-1}$ arasında değişmektedir [3]. Ayrıca, Güneş benzeri yıldızlar bulgurlanma etkisi sebebiyle yaklaşık $2 \mathrm{kms}^{-1}$ seviyesinde bir dikine hız değişimi göstermektedir [4]. Yıldızın doğası kaynaklı bu etkiler bazen gezegen(ler) kaynaklı dikine hız değişimleri ile kolayca karıştırılmaktadır [5]. Bunun için dikine hız ölçümlerinde bu türden etkilerin, gezegen(ler) kaynaklı etkilerden ayırt edilmesi son derece önemlidir.

Geç tayf türü yıldızlarda ki bulgurlanma, zonklama, manyetik çevrim ve yüzey lekeleri gibi bu tür etkiler direk olarak tayf çizgilerini etkilemekte ve çizgi profillerinde asimetrilere yol açmaktadır. $\mathrm{Bu}$ tayf çizgi asimetrilerini çalışmanın yaygın yöntemlerinden birisi çizgi ortay analizidir [6-12]. Çizgi ortaylarının biçimi yıldız kaynaklı etkilerden önemli derece etkilendiğinden, gezegen(ler) kaynaklı dikine hız değişimlerini ayırt etmede oldukça kullanışlıdır. Çünkü gezegen(ler) tayf çizgi profillerinde asimetriye sebep olmamaktadir.

G türü dev bir yıldız olan HD 199719'un ön çalışması 2016 yılında uluslararası bir toplantıda sunuldu [13]. Ancak yıldızın dikine hız ölçümlerinde (Şekil 1) görülen 100 $\mathrm{msn}^{-1}$ mertebesindeki değişiminin kökeni hakkında bir tartışma yapılmadı. Bu çalışmada ise, yıldıza ait bu değişimin kaynağı araştırıldı. Sırasıyla kısım 2.1 ile TUG'da ve Ankara Üniversitesi Kreiken Rasathanesi (AUKR)'nde elde edilen tayfsal ve fotometrik gözlem verilerin indirgenmesi, kısım 2.2'de yıldızın karakteristik özellikleri, kısım 2.3'te çizgi ortay analizleri ve 2.4 'te eşdeğer genişlik ölçüm analizleri, son olarak kısım 3 'te ulaşılan bulgular ve kısım 4'te elde edilen sonuçlar sunuldu.

\section{Materyal ve Metot}

\subsection{Veri indirgemesi}

Analizlerde kullanılan HD 199719'a ait 145 adet tayf gözlemleri TUG'da, 150 cm'lik Rusya-Türkiye Teleskobu (RTT150) kullanılarak Coude Echelle Tayfçekeri (CET) ile 2010 Haziran - 2017 Aralık ayları arasında elde edildi. Ayrıca verilere ait dikine hız ölçümlerinde hassas dalga boyu referansı sağlamak için tayfçekerin silit açıklığının hemen önünde iyot $\left(\mathrm{I}_{2}\right)$ hücresi kullanıldı. Kullanılan CET tayfçekerinin dalga boyu aralığı $4000 \AA$ ile $8000 \AA$ aralığında olup çözünürlüğü (R) 55000'dir. Tüm veriler için 1800 sn pozlama süresi verilerek piksel başına $(\mathrm{S} / \mathrm{N})=80-150$ sinyal/gürültü oranı elde edildi.

Hedef y1ldızın fotometrik verileri AUKR'de bulunun $35 \mathrm{~cm}$ 'lik T35 teleskobu ile elde edildi. Gözlemlerde görüş alanı 13 yay dakikası x 13 yay dakikası ve piksel başına plak ölçeği 0.75 yay saniyesi olan 1024 x 1024'lük ALTA U47 CCD kamerası kullanıldı. 
Fotometrik verilerde hassasiyeti arttırmak amacıyla odak-dışı (ing.defocuse) gözlem tekniği kullanıldı. Böylece fotometri hassasiyetin $\mathrm{R}$ bandı için 3-4 mili-kadir (mmag) mertebesinde olduğu görüldü.

Echelle gözlem verilerinin indirgenmesi (bias düzeltmesi, normalize flat düzeltmesi, saçılmış 1şık düzeltmesi, tayfların çıkarılması ve dalgaboyu kalibrasyonu) IRAF (Image Reduction and Analysis Facility) yazılım paketi kullanılarak standart yolla yapıldı. Yıldızın dikine hız ölçümleri (Şekil 1) yıldız $+\mathrm{I}_{2}$ bileşke tayfından Butler vd. [14] tarafından temel alınan analiz tekniğine göre özel bir IDL[15] (Interactive Data Language) kodu ile elde edildi.

Odak-dış1 fotometrik gözlem verilerinin indirgenmesi standart fotometrik indirgeme adımları (bias, dark ve flat düzeltmesi, hizalama işlemi ve fotometri) ile IRAF kullanılarak yapıldı. Yıldızın elde edilen 1şık ölçümleri Şekil 2’ de verildi.

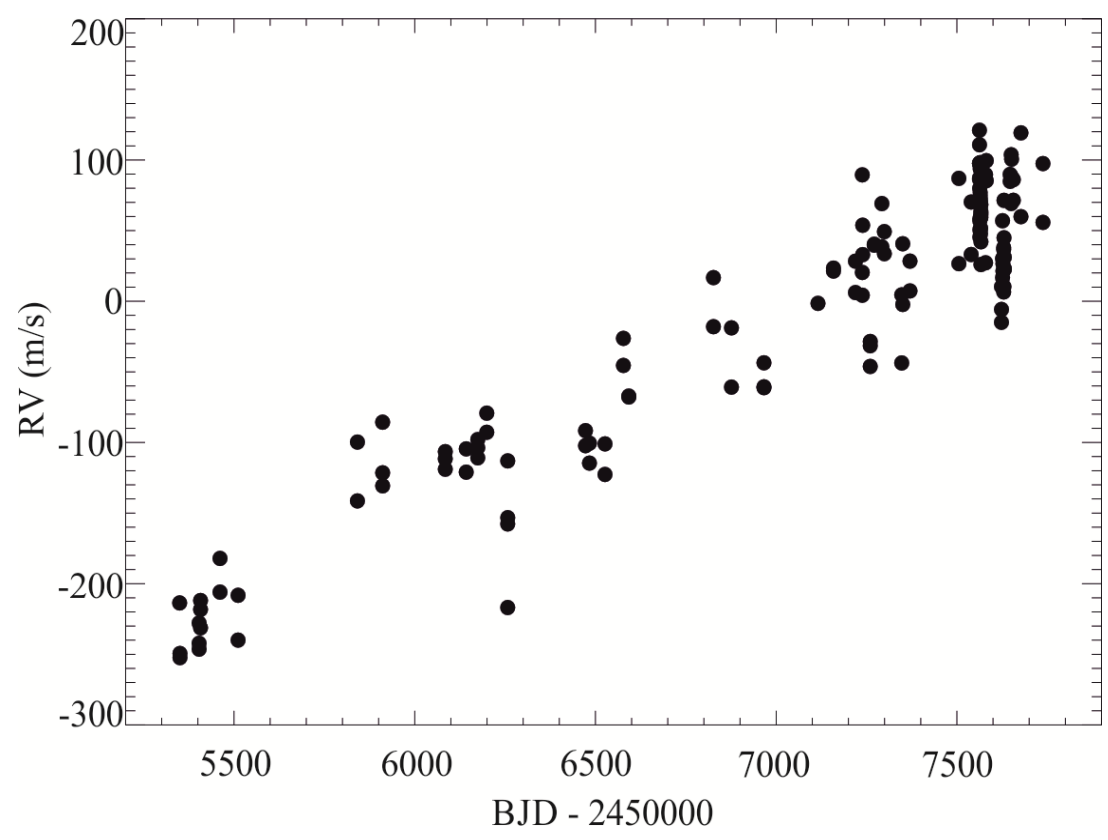

Şekil 1. HD 199719’a ait hassas dikine hız ölçümleri

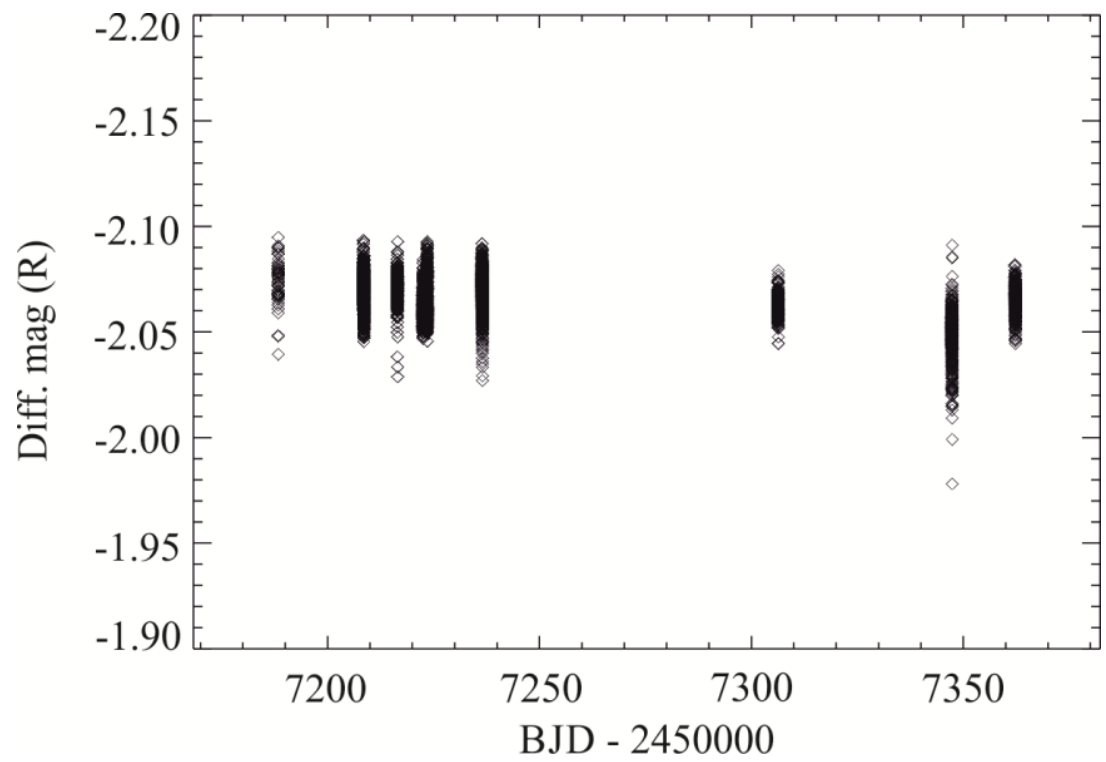

Şekil 2. HD 199719’a ait Bessel R 1şıłk ölçümleri 


\subsection{Yuldız özellikleri}

HD 199719 (HIP 103516) görsel parlaklığ $\mathrm{V}=6.57$ kadir olan ve $\mathrm{B}-\mathrm{V}=0.89$ renk ölçeğine sahip G8 tayf türünden dev bir yıldızdır. Yıldızın 5.025 mili-yay saniyesi değerindeki HIPPARCOS [16] paralaksı ve yıldızalararası sönümleme miktarı için seçimli sönümleme oranı $\left(\mathrm{R}_{\lambda}\right) 3.1$ olarak görsel mutlak parlaklığ $\mathrm{MV}_{V}=0.075 \mathrm{kadir}$ olarak belirlendi. Bu hesaplamada Schlegel vd. 'nin [17] toz haritalarından elde edilen sönümleme katsayısı $\mathrm{A}_{\mathrm{v}}$ kullanıldı.

Yıldıza ait fiziksel ve atmosferik parametreleri tayfın $\mathrm{I}_{2}$ soğurma bölgelerinin dışında kalan bölgelerdeki Fe I, Fe II, Mg Ib triblet çizgileri, Na I D doublet çizgileri, Ca I, H $\alpha$, $\mathrm{H} \beta$ ve $\mathrm{H} \gamma$ çizgilerinin eşdeğer genişlik ölçümlerinden elde edildi. Çizgilerin eşdeğer genişlik ölçümleri için IDL programlama dilinde yazılan grafik ara yüzü BINMAG2 [18] kullanıldı. Analizlerde kullanılan sentetik tayflar Synth3 [19] koduyla VALD [20] veri tabanından alınan çizgi listeleri yardımıyla oluşturuldu. Kimyasal bolluk analizleri ve sentetik tayf üretmek için gerekli model atmosferler dosyaları ATLAS9 [21] model atmosfer programı kullanılarak oluşturuldu.

Yıldızın dönme hızını belirleyebilmek için orta şiddetli örtüşmemiş temiz tayf çizgilerinin profillerine Gauss fiti yapıldı. Ölçülen eşdeğer genişlikleri ile uyartılma ve iyonizasyon dengeleri kullanılarak yıldızın nihai atmosfer parametreleri belirlendi ve Tablo 1'de verildi. Analizler sonucunda yıldızın etkin sıcaklığı ( $\left.\mathrm{T}_{\text {eff }}\right)$, yüzey çekim ivmesi $(\log g)$, metal bolluk değeri $([\mathrm{Fe} / \mathrm{H}])$, mikrotürbülans hızı $\left(\mathrm{V}_{\mathrm{t}}\right)$ ve dönme hızı (vsini) belirlenmiş oldu, Bunların yanı sıra son olarak, yıldızın bolometrik parlaklık düzeltmesi (B. C.), etkin sıcaklık ve uzaklık bilgilerinden hareketle de yarıçap ve kütle değerleri hesaplandi.

Tablo 1. HD 199719 Yildızının Fiziksel ve Atmosfer Parametreleri

\begin{tabular}{cc}
\hline Parametre & Değer \\
\hline Tayf Türü & G8 III \\
V(mag) & 6.54 \\
B - V & 0.89 \\
$\pi$ (mas) & 5.025 \\
B.C. $_{\mathrm{M}_{\mathrm{v}}}$ & -0.252 \\
$\mathrm{~A}_{\mathrm{v}}$ & $0.075 \pm 0.013$ \\
$\mathrm{~T}_{\text {eff }}(\mathrm{K})$ & 0.062 \\
$\operatorname{logL}\left(\mathrm{L}_{\mathrm{Güneş}}\right)$ & $4850 \pm 100$ \\
$\log g(\mathrm{cgs})$ & $1.995 \pm 0.018$ \\
$\mathrm{M}\left(\mathrm{M}_{\mathrm{Güness}}\right)$ & $2.45 \pm 0.02$ \\
$\mathrm{R}\left(\mathrm{R}_{\mathrm{Güness}}\right)$ & $2.06 \pm 0.17$ \\
{$[\mathrm{Fe} / \mathrm{H}](\mathrm{dex})$} & $14.13 \pm 0.58$ \\
$\mathrm{~V} \sin i(\mathrm{~km} / \mathrm{sn})$ & $0.03 \pm 0.05$ \\
$\mathrm{~V}_{\mathrm{t}}(\mathrm{km} / \mathrm{sn})$ & $1.9 \pm 0.2$ \\
\end{tabular}

\section{3 Çizgi ortay analizi}

Çizgi ortay hesaplamaları için, gözlemsel tayflar ile aynı dalga boyu aralığına sahip sentetik tayflar üretildi. Söz konusu sentetik tayflar yıldızın atmosfer parametrelerine bağlı olarak model atmosfer programları ile oluşturuldu.

Gözlemsel tayflara sentetik tayflar ile çapraz korelasyon uygulanarak ortalama çizgi profilleri ve bu profillerin orta noktaları hesaplandı. Bu orta noktalardan geçen eğriyi 
(çizgi ortayını) belirlemek için IDL ile özel bir kod yazıldı. Geliştirilen analiz kodu ile 145 adet tayf çizgisi için aynı işlemler uygulandı.

Çizgi ortay analizleri $6000 \AA$ - $7210 \AA \AA$ dalga boyu aralığındaki iyodinsiz bölgeler için yapıldı. Analizde bu dalga boyu aralığındaki tüm tayf çizgilerini kullanmak yerine göreceli olarak orta şiddetli ve örtüşmemiş temiz çizgiler seçilerek maskeleme yöntemi uyguland1. Bu yöntemde toplam 18 adet çizgi kullanıldı ve maskeleme işlemi hem gözlemsel tayflara hem de sentetik tayflara uyguland.

Belirlenen ortayların asimetrilerini niceliksel olarak tanımlayabilmek için ortay ölçütleri kullanıldı. Bu çalışma kapsamında ortayın ters eğimi (BIS, ing. Bisector inverse slope), ortayın kapladığı hız alanı (BVS, ing.bisector velocity span), ortayın hız eğriliği (BVC, ing. bisector velocity curvate) ölçütleri kullanıldı. BIS için çizgi derinliğinin \%10 - \%40 arasındaki hız değerlerinin ortalaması vt ve \%55 - \%90 arasındaki hız değerlerinin ortalaması vb olarak iki adet akı seviyesi tanımlandı [12]. BIS ölçütü bu iki aralıktan Denklem 1 ile hesaplanmaktadır.

$$
B I S=v_{t}-v_{b}
$$

BVS ve BVC için ise çizgi derinliğinin farklı üç akı seviyesinden belirlendi. Bunlar; $v_{1}$ $=\% 5-\% 25, v_{2}=\% 35-\% 55, v_{3}=\% 65-\% 85$ 'tir [22]. Bu iki ölçüt ise Denklem 2 ve Denklem 3 ile hesaplanmaktadır.

$$
\begin{gathered}
B V S=c_{b}=\left(v_{3}-v_{2}\right)-\left(v_{2}-v_{1}\right) \\
B V C=v_{1}-v_{3}
\end{gathered}
$$

\subsection{Eşdeğer genişlik ölçümü}

Güneş benzeri yıldızlarda dikine hız değişimine sebep olan homojen olmayan yüzey özellikleri (yıldız aktivitesi kaynaklı yüzey lekeleri vb.) gibi mekanizmaların varlığını kontrol etmek için kromosferik aktivite belirteci olarak bazı çizgiler kullanılmaktadır. $\mathrm{Bu}$ çalışmada da yaygın olarak kullanılan $\mathrm{H \alpha}(\lambda 6562.852)$ ve $\mathrm{H} \beta(\lambda 4861.33)$ çizgileri kullanıldı. Bu çizgiler için yapılan eşdeğer genişlik ölçümlerinde, örtüşmüş çizgilerden etkilenmemek adına çizgi merkezinden itibaren $\mathrm{H} \alpha$ için $\pm 1.0 \AA$ ve $\mathrm{H} \beta$ için $\pm 0.8 \AA$ olarak kabul edildi [23]. Ölçümler temelde gauss fiti ile yapıldı. $\mathrm{Bu}$ iki çizginin tüm gözlemsel tayflar için eşdeğer ölçümleri yapıldı.

\section{Bulgular}

Maskeleme yöntemi ile elde edilen BIS, BVS ve BVC ortaylarına ait sonuçların dikine hız ölçümlerine göre dağılım grafikleri ve ortayların Lomb-Scargle yöntemi ile elde edilen dönem analizlerine ait sonuçlar sırası ile Şekil 3'te verildi. Grafiklerin korelasyon katsayısı $\left(\mathrm{R}^{2}\right)$ ve ki-kare $\left(\chi^{2}\right)$ değerleri ise sırasıyla BIS, BVC ve BVS grafikleri için $\mathrm{R}^{2}{ }_{\mathrm{BIS}}=0.0218, \mathrm{R}^{2}{ }_{\mathrm{BVC}}=0.022, \mathrm{R}^{2}{ }_{\mathrm{BVS}}=0.015, \chi^{2}{ }_{\mathrm{BIS}}=0.923, \chi^{2}{ }_{\mathrm{BVC}}=1.141, \chi^{2}$ BVS $=$ 0.140 olarak hesaplandı. $\mathrm{Bu}$ değerler dikine hızlar ile ölçütler arasında bir korelasyondan söz edilmesinin mümkün olmadığını açıkça göstermektedir. Dönem diyagramlarının sonuçlarında yüksek piklerin güvenirliliğinin ölçülmesi için tipik bir yaklaşım olan FAP (ing. False Alarm Probability) değerleri kullanıldı.

Analizlerde kullanılan çizgi ortaylarının tümü herhangi bir kaydırma veya ölçeklendirme yapılmaksızın üst üste çizdirildi ve Şekil 4'te verildi. H $\alpha$ ve $\mathrm{H} \beta$ 
çizgilerinin eşdeğer genişlik ölçümlerinin zamana göre grafikleri ve dönem analizleri Şekil 5 'te yer almaktadır.

\section{Sonuç ve Yorum}

Bu çalışmanın öncelikli hedefi HD 199719' un dikine hız değişiminin kaynağının araștırılması ve irdelenmesidir. $\mathrm{Bu}$ bağlamda yıldızın sistematik gözlemlerinin analizlerinden elde edilen çizgi ortay ölçütleri ve çizgi asimetrilerinin dikine hız ile ilişkisi ortaya konulmaya çalışıldı.
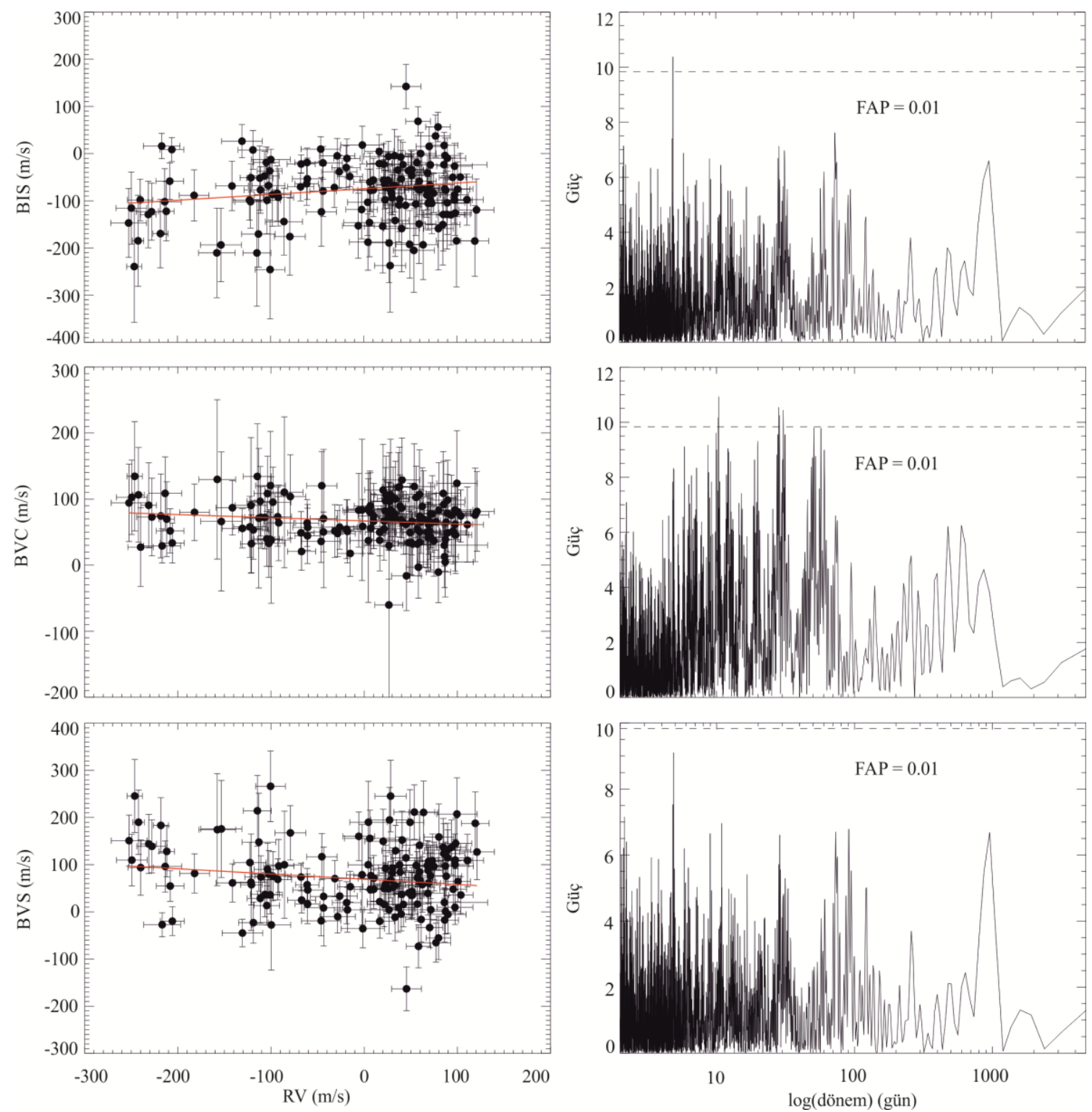

Şekil 3. BIS, BVS ve BVC' nin dikine hıza göre değişimi (sol). BIS, BVS ve BVC için Lomb -Scargle yöntemiyle elde edilen dönem analizi (sağ).

Çizgi asimetrilerini nicel olarak ifade etmemizi sağlayan BIS, BVC ve BVS ölçütlerinin grafiklerine bakıldığında, dikine hız ile bir korelasyon göstermediği açıkça görülmektedir. Yapılan doğrusal fitlerin eğrileri bunu açıkça ortaya koymaktadır. Bu durumda, bu bulgular bize yıldızın doğası kaynaklı eteklerin dikine hız değișiminde önemli bir rol almadığını düşündürmektedir. Ancak ortay ölçütleri için elde edilen 
dönem analiz grafiklerinde, BIS için 4.88 günlük ve BVC için 10.36 günlük dönemleri işaret eden pikler görülmektedir. Bulunan bu kısa dönemler ilk bakışta, özellikle geç tayf türü yıldızların yüzeyinde görülen düşük genlikli salınımlardan kaynaklı olabileceğini düşündürmektedir.

Ölçütlere ait grafikler dikine hıza göre bir değişim göstermediğinden manyetik aktivite etkisinden kaynaklı bir değişim olmadığı sonucuna varılabilir. Fakat aktif bölgeler hem soğuk lekeleri hem de sicak plaj bölgeleri ile faküla bölgelerini içerdiğinden ve bunlar birbirlerine göre zıt yönlerde olabilecek ortak etkileri nedeniyle, yıldızın çizgi profillerindeki değişimler fark edilmeyebilir. Bunun yanı sıra hassas dikine hız ölçümlerinin grafiği (Şekil 1) yukarı yönde devam eden ve oldukça uzun dönemli bir değişimin varlığını göstermektedir. Bu değişimin sebebi uzun dönemli manyetik çevrim gibi bir etkinin varlığını veya görülmeyen bir bileşenin varlığını gösteriyor olabilir.

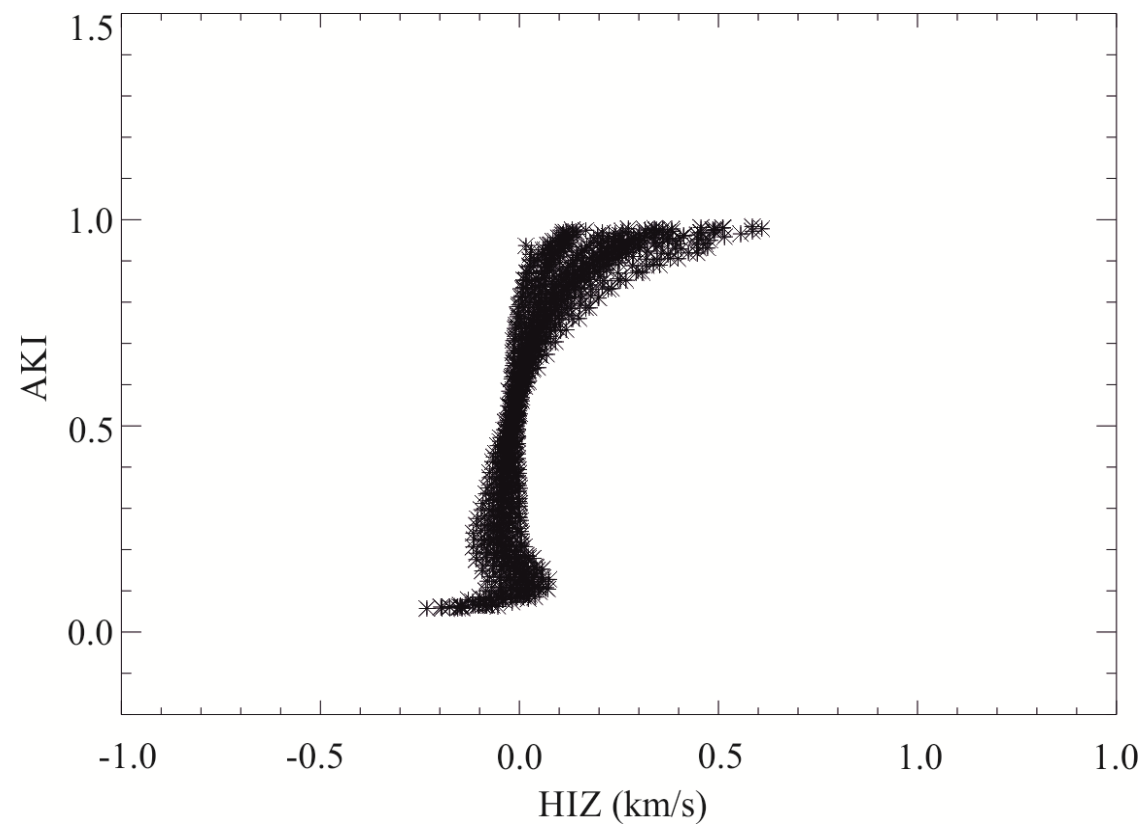

Şekil 4. Elde edilen tüm çizgi ortayları.

Elde edilen ortayların, ölçeklendirme yapılmadan üst üste çizdirilen grafiğinde ortay şekillerinin asimetrik yapılara sahip ve her bir şeklin yapısının biçimsiz bir ' $\mathrm{C}$ ' şeklinde olduğu da görülmektedir [24]. Bu grafiğe bakıldığında yıldızın yüzeyinde var olan bulgurlanma (granülasyon) hareketinden söz edilebilir. Bu etki özellikle geç tayf yıldızların yüzeyinde sürekli ve birkaç gün civarında dönemlere sahip olabilir.

$H \alpha$ ve $H \beta$ için yapılan eşdeğer genişlik ölçümlerinde, $H \alpha$ büyük dönemli bir değişim göstermektedir. Bu değişim yıldızın sahip olduğu manyetik çevrimi kaynaklı olabilir. $\mathrm{H} \beta$ için elde edilen grafikte ise herhangi bir değişim söz konusu değildir.

Yıldıza ait fotometrik gözlemlerinden görüldüğü üzere önemli bir 1ş1k değişimi (bileşen veya yıldızın doğası kaynaklı) olmadığı açıkça görülmektedir (Şekil 2). Yaklaşık 200 günü kapsayan bu verilerin ortalama standart sapması 20 mili-kadir civarındadır. $\mathrm{Bu}$ bulgular uzun dönemde sistemde önemli bir fotometrik değişimin olmadığını gösterir. Ancak, gecelik gözlemlere bakıldığında ise bu değişim 50-70 mili-kadir civarlarındadır. Bu saçılmaların ana kaynağı ise bulgurlanma ve düşük manyetik aktivite kökenli etkiler olabilir. 
Sonuç olarak, yıldızın hem ortay biçimlerine hem de ölçüt grafiklerinde yıldızın yüzeysel lekelerinden kaynaklı etkilere ilişkin bir kanıt elde edilememiş olsa da, yıldız da kısa dönemli dikine hız değişimlerine neden olabilecek manyetik etkinlik tamamen dışlanamaz. Ortay biçimlerindeki çok biçimsiz ' $\mathrm{C}$ ' şekline bakılarak, yıldızda bulgurlanma etkisinin varlığ düşünülse de, bu etkinin tipik dönemlerinin birkaç gün civarında olması dikine hızda ki uzun dönemli değişimi açıklayamamaktadır. Bulunan dönemler y1ldızda meydana gelen çapsal veya çapsal olmayan zonklamalardan (G-K türü dev yıldızlarda birkaç gün mertebelerde dönemlere sahiptir ve çizgi biçimlerinde asimetri yaratır) ve bulgurlanma (granülasyon) hareketinden kaynaklı olabilir. $\mathrm{H} \alpha$ çizgisi için yapılan analizlere ve dikine hızın zamana göre değişim grafiğine dayanarak birkaç y1l mertebesinde bir döneme sahip manyetik çevrimden söz edilebilir. Her ne kadar yıldız doğası kaynaklı etkilerden şüpheleniliyor olunsa da dikine hız ölçümlerinde görülen uzun dönemli değişim yıldız altı bir cisimden veya bir ötegezegenden kaynaklı olma ihtimali de göz önünde bulundurulmalıdır.
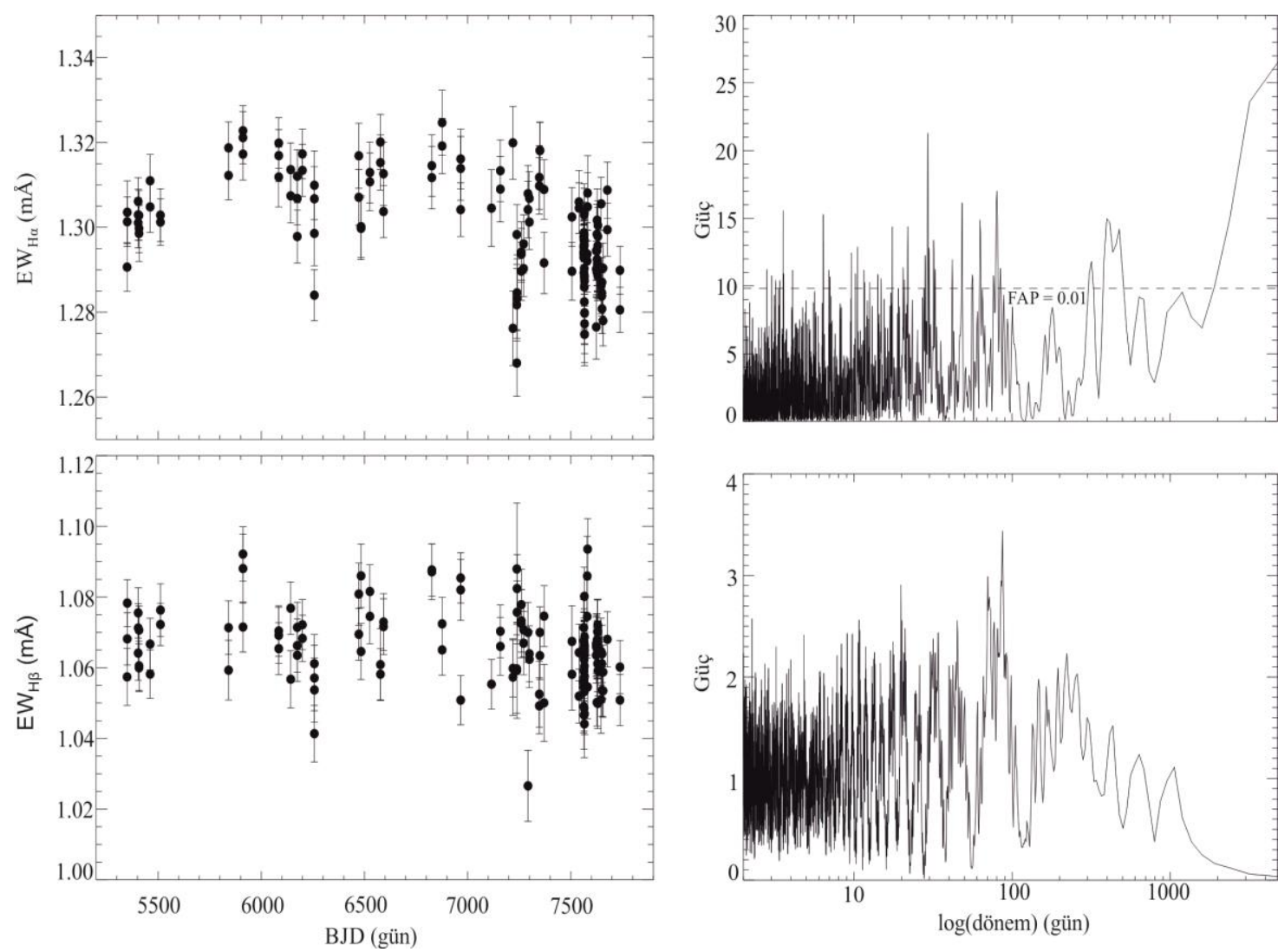

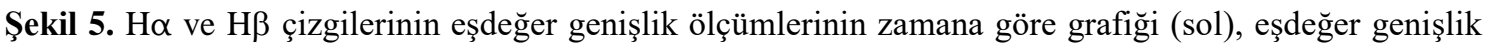
ölçümlerinin dönem analizi (sağ).

\section{Araştırmacıların Katkı Oranı Beyanı}

Didem Dilan IZCI: Araştırma, Orijinal Taslak Yazımı, İnceleme, Düzenleme, Görselleştirme

Mesut YILMAZ: Proje Yönetimi, Kaynak/Materyal/Malzeme Temini, Denetim/Gözlem/Tavsiye, Araştırma, Doğrulama, İnceleme ve Düzenleme

\section{Destek ve Teşekkür Beyanı}

Çalışma kapsamında yıldızın gözlemlerinde kullanılan RTT150 (Antalya'da Tübitak Ulusal Gözlemevinde bulunan 1,5 m'lik teleskop) ve 15ARTT150-718 proje kapsamındaki destekleri için TÜBITTAK'a teşekkür ederiz. Fotometrik gözlemlerin gerçekleştiği Ankara Üniversitesi Kreiken Rasathanesi'ne desteklerinden dolayı teşekkür ederiz. Bu çalışma 114F099 numaralı TÜBİTAK Projesi kapsamında desteklenmiştir. 


\section{Çatışma Beyanı}

Bu çalışmanın yazarları olarak herhangi bir çatışma beyanımız bulunmamaktadır.

\section{Etik Kurul Onayı ve/veya Aydınlatılmış Onam Bilgileri}

$\mathrm{Bu}$ çalışmanın yazarları olarak herhangi bir etik kurul onayı ve/veya aydınlatılmış onam bilgileri beyanımız bulunmamaktadır.

\section{Kaynakça}

[1] V. V. Makarov, C. A. Beichman, J. H. Catanzarite, D. A. Fischer, J. Lebreton, F. Malbet, and M. Shao, "Starspot jitter in photometry, astrometry and radial velocity measurements," The Astrophysical J.,707(1), L73 - L76, 2009.

[2] S. H. Saar and R. A. Donahue, "Activity-Related Radial Velocity Variation in Cool Stars," The Astrophysical J., 485(1), 319 - 327,1997.

[3] C. J. Schrijver and C. Zwaan, Solar and Stellar Magnetic Activity. Cambridge (Reino Unido): Cambridge University Press, 2000.

[4] G L. Lindegren and D. Dravins, "The fundamental definition of "radial velocity," Astronomy \& Astrophysics, 401(3),1185 - 1201, 2003.

[5] D. Queloz, G. W. Henry, J. P. Sivan, S. L. Baliunas, J. L. Beuzit, R. A. Donahue, M. Mayor, D. Naef, C. Perrier, and S. Udry, "No planet for HD 166435," Astronomy and Astrophysics, 379, 279 287, 2001.

[6] D. F. Gray, Lectures on Spectral-line Analysis: F,G, and K stars. Arva: Ontario Gray, 1988, pp. 308.

[7] A. P. Hatzes, M. Fridlund, G. Nachmani, T. Mazeh, D. Valencia, G. Hébrard, L. Carone, M. Pätzold, S. Udry, F. Bouchy, M. Deleuil, C. Moutou, P. Barge, P. Bordé, H. Deeg, B. Tingley, R. Dvorak, D. Gandolfi, S. Ferraz-Mello, G. Wuchterl, E. Guenther, T. Guillot, H. Rauer, A. Erikson, J. Cabrera, S. Csizmadia, A. Léger, H. Lammer, J. Weingrill, D. Queloz, R. Alonso, D. Rouan, and J. Schneider, "The Mass of CoRoT-7b," The Astrophysical J., 743 (1), 75, 2011.

[8] O. Lozitsky, "Creation and usage of program code for strong subtelescopic solar magnetic field diagnostics," in Proc. 21th Young Scientists' Conference on Astronomy and Space Physics, Kyiv, 2014, pp. 34-35.

[9] X. Dumusque, N. C. Santos, S. Udry, C. Lovis, and X. Bonfils, "Planetary detection limits taking into account stellar noise. II. Effect of stellar spot groups on radial-velocities," Astronomy \& Astrophysics, 527, A182, 2011b.

[10] I. Boisse, F. Bouchy, G. Hébrard, X. Bonfils, N. Santos, and S. Vauclair, "Disentangling between stellar activity and planetary signals," Astronomy \& Astrophysics, 528, A4, 2011.

[11] S. Aigrain, F. Pont and S. Zucker, "A simple method to estimate radial velocity variations due to stellar activity using photometry," Monthly Notices of the Royal Astronomical Society, 419 (4), 3147-3158, 2012.

[12] M. Y1lmaz, B. Sato, I. Bikmaev, S. O. Selam, H. Izumiura, V. Keskin, E. Kambe, S. S. Melnikov, A. Galeev, İ. Özavc1, E. N. Irtuganov, and R. Ya Zhuchkov, "A Jupiter-mass planet around the K0 giant HD 208897," Astronomy \& Astrophysics, 608, A14,2017.

[13] M. Yılmaz, S. O. Selam, B. Sato, I. Bikmaev, H. Izumiura, V. Keskin, and E. Kambe, "The line bisectors of G type giant star HD 199719," in Proc. The 19th Cambridge Workshop on Cool Stars, Stellar Systems, and the Sun, Uppsala, 2016.

[14] R. P. Butler, G. W. Marcy, E. Williams, C. McCarthy, S. S. Vogt, and P. Dosanjh, “Attaining doppler precision of 3 M s-1," Publications of the Astronomical Society of the Pacific, 108, 500, 1996.

[15] Networks[Online]. Available: https://www.harrisgeospatial.com/Software-Technology/IDL\#language

[16] F. Van Leeuwen, "Validation of the new Hipparcos reduction," Astronomy \& Astrophysics, 474, 653-664, 2007.

[17] D. J. Schlegel, D. P. Finkbeiner, and M. Davis, "Maps of duts infrared emission for use in estimation of reddening and cosmic microwave background radiations foregrounds," The Astrophysical J., 500, 525-553, 1998.

[18] O. Kochıkhov. Networks[Online]. Available: https://www.astro.uu.se/ oleg/binmag.html

[19] P.O. Kochukhov, "Spectrum synthesis for magnetic, chemically stratified stellar atmospheres," in Proc. Physics of Magnetic Stars. Proceedings of the International Conference, Uppsala, 2007, 109.

[20] T. Ryabchikova, N. Piskunov, R. L. Kurucz, H. C. Stempels, U. Heiter, Yu Pakhomov and P S Barklem, "A major upgrade of the VALD database," Physica Scripta (IOP), 90 (5), 054005 (4pp), 2015. 
[21] F. Castelli and R. L. Kurucz, "New grids of ATLAS9 model atmospheres," in Proc. IAU Symposium Modelling of Stellar Atmospheres, 2004.

[22] T. H. Dall, N. C. Santos, T. Arentoft, T. R. Bedding, and H. Kjeldsen, "Bisectors of the Cross Correlation Function Applied to Stellar Spectra," Astronomy \& Astrophysics, 454, 341-348 2006.

[23] B.C. Lee, I. Hank, M. G. Park, D. E. Mkrtichan, A. P. Hatzes, G. Jeong, and K. M. Kim, "Longperiod variations in the radial velocity of spectroscopic binary $\mathrm{M}$ giant $\mu$ Ursae Majoris," The Astronomical J., 151(4), 106, 2016.

[24] D. F. Gray, The Observation and Analysis of Stellar Photospheres, 3rd edition, Cambridge, Press: Cambridge University, 533, 2005. 